\title{
Promoting Critical Thinking through Children's Experiential Learning
}

\author{
Desiani Natalina Muliasari \\ Universitas Pendidikan Indonesia, Bandung, Indonesia \\ Corresponding e-mail: desianinm@upi.edu
}

\begin{abstract}
Critical thinking is a strategic competence that becomes the focus in Indonesia education today. Being a critical thinker is not an easy process. It has to start since early childhood. Critical thinking involves active engagement with ideas. Thus, it requires efforts. (Roche, 2015). In promoting critical thinking for children, a teacher should engage the students to a learning experiences that is in accordance with the children characteristics. The article describes the learning experiences of children in doing some Indonesia traditional plays. Plays are important in the early childhood learning. Unfortunately, traditional plays that valued of its philosophy are rarely played by children today. Most children in Indonesia tend to be interested in playing games in their tablets, phone or computer. Children sit for hours and eyes keep to the display while they are playing their games. No active engagement with peers, body movement, and philosophies. Sundanese plays carried traditional philosophies such as cooperating, helping others, discipline, responsibility, etc. The purpose is not only preserving traditional plays that valued traditional philosophies, but also it is practicing the children's critical thinking in a fun and active way. Some aspects of critical thinking also revealed in the activities of playing traditional plays.
\end{abstract}

Keywords: Critical Thinking, Experiential Learning

\section{INTRODUCTION}

People is demanded to have strategic competence in the $21^{\text {st }}$ century and one of the skill is critical thinking. Critical thinking becomes the concern as it involves mental processes, and strategies of people to evaluate, to solve, and to make decisions of a problem they encounter (Sternberg, 1986; Ennis, 1996). Thus, to have such competence, it needs efforts and processes as it is not an easy skill to achieve. It should be started as early as possible and early education is the best starting point (Ennis, 1996). Unfortunately, there was still limited research and evidence regarding the critical thinking in early childhood education. This article describes part of a research related to developing critical thinking for children. In our research, we did not analyse the children's critical thinking but we were developing and promoting critical thinking to children as there were many aspects of critical thinking to be achieved. To promote children critical thinking ability, they needed to experience activities that would develop their critical thinking skill. Experiential learning became the choice as it would involve the students through learning by doing and it would increase knowledge and develop skill (Kolb Kolb, 2008). Hence, we needed to create activities that would engage the children into the critical thinking process and practice their critical thinking skill experiences. The activities created should also consider the children basic nature and characteristics. One of the activities we decided to choose is play. Play suited for children as it provides opportunities for children to experience activities in a meaningful, purposeful way, and fun (Plantinga \& Trainor, 2008). In Indonesia, there are so many Traditional plays exist. Regrettably, traditional plays were rarely played by the children and it was almost forgotten. Children tend to play through gadget or computer that less physical activities and social interaction with their peers (Plowman, Mc. Peck, and Stephen, 2010). Traditonal plays that valued with its philosophies of social interaction, strategic thinking, and moral education needed to be preserved. Therefore, in the research the students engaged themselves in the experiential learning of doing the traditional plays to promote their critical thinking skill. 


\section{LITERATURE REVIEW}

\subsection{Critical Thinking Skill}

There are some arguments that define critical thinking as part of high order thinking skill, others also argue that critical thinking is the same as high order thinking skill. Above all the arguments basically critical thinking pursues the matureness of thinking. It involves mental process, star aegis, and sources to examine, review, make reasonable decisions and solve the problem (Sternberg, 1986; Ennis, 1996). Cottrell (2005) and Stedman \& Adams (2012) explain that critical thinking will help an individual to identify various information, select and choose the information needed and it also need an effort to gather information and to analyse that before making a decision (Roche,2015). Moreover, to be a critical thinker is not an easy task as there are some aspects that need to be fulfilled by an individual. Ennis (1996) elucidates the aspects as FRISCO; Focus, Reasons, Inference, Situations, Clarity, and Overview. Many research related to critical thinking had Ennis as their grounded theory. Further Ennis describes that critical thinking best started since early primary schoolers. It becomes good starting point as the children are in the golden age era where they are able to grasp anything faster and better. Brookfield (1987) hand in hand with Fisher (2006 in Roche, 2015: 14) detail that the aspects of critical thinking that are going to be promoted to the children should cover curios (asking deep and interesting questions), collaborative (through generating and building on ideas), critical (through giving reasons and evidence), creative (through generating and building on ideas), and caring (through developing awareness of self and care of others). Additionally, in promoting critical thinking to children, it should be carried out in a process that suitable for the children development and should be planned in stages.

\subsection{Experiential Learning}

Experiential learning became one way to involve individuals to direct experiences especially children. The children are involved in active engagement with activities, learning by doing (Lewis and Williams 1994, IIlleris, 2007), and concrete experiences (Kolb\&Kolb, 2005). It is important for children because they actively transform the ideas into practice. Further, some theories describe that experiential learning Theorist of Experiential learning developed by Kolb and Kolb (1984) explained that experiential learning should go through learning cycles. Those includes Concrete Experience - (CE), Reflective Observation - (RO), Abstract Conceptualization - (AC), and Active Experimentation - (AE).

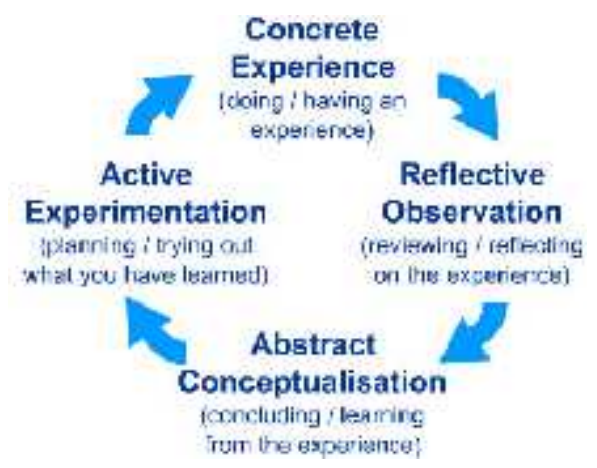

Figure 1: Experiential Learning Cycles (Kolb \& Kolb, 1984)

This theory was argued by Seaman (2008). Seaman described that learning cycles era has over. He applies that experiential learning involved experience, reflect and critique. Out of all arguments, basically I applied experiential learning in this study as direct experiences, hand-on physical activities that actively engage the children in a fun and playful activities.

\section{RESEARCH METHOD}

\subsection{Participants}

The participants of the study were 22 children age 6 and 7 of Smart School located in one of the city in Indonesia.

\subsection{Data Collection and Data Analysis}

The research applied Educational Design Research. The data was collected through observation and interview. The observation was conducted to observe the student's activities during they played some traditional plays. After the students engaged in the traditional plays they were interviewed. The interview was semi-structured and related to their opinions related to the traditional plays they had played. The observation and interview were all recorded and analysed qualitatively to answer the research questions addressed in the study. The analysis triangulated all data needed. The data were interpreted, reviewed, and discussed. 


\section{RESULTS}

The children experienced two traditional plays, namely BoyBoyan. The traditional play Boyboyan was chosen and carried out based on the following considerations:

- $\quad$ It had social interaction. All plays were done in groups of minimum 5 people of each group.

- It had a competition between groups. Competition would carry supportive, honest, competitiveness, responsibility values.

- It involved Hands-on physical activities.

- It involved strategic skill of the competition Babayan requires children physical activities as running and throwing a ball. The following are the stages the children should experience in the play:

- The children were divided into two groups.

- One group was called the attacker team and the other one is called the defender team.

- The attacker should throw a ball to the structured broken tiles. If the tiles have fallen down, the attacker immediately run to avoid the ball. The distance between the broken tiles and the place to throw is around three to four meters.

- $\quad$ The defender team should get the ball quickly and throw it and hit the attacker team. Those who get hit cannot join the team again.

- The defender should keep the broken tiles unstructured/unarranged until the attacker team has lost their members.

- The attacker should arrange again the broken tiles until its last pieces while avoiding the ball from the defender.

- If the attacker is succeeded in arranging the broken tiles, then the team wins. If the defender is succeeded in keeping the broken tiles unstructured and the attacker team has lost its members, then the defender team wins.

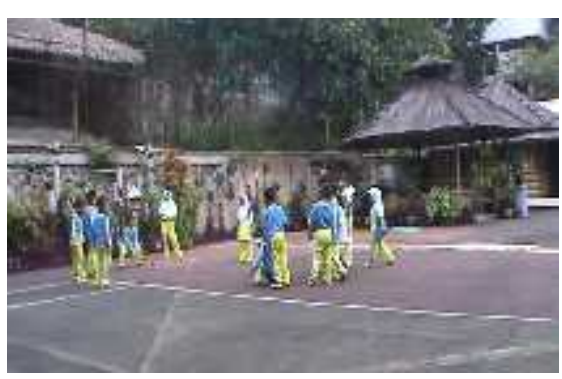

Figure 2: Process of Boyboyan

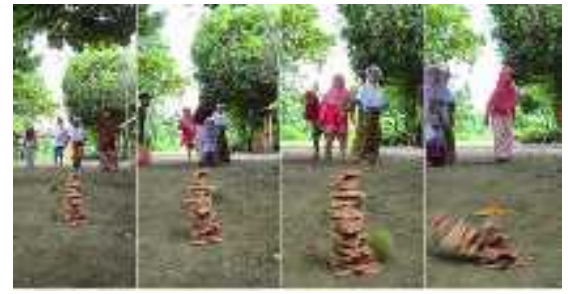

Figure 3. structured broken tiles and the fallen broken tiles (adoptedfrom specialpengetahuan.blogspot.com)

After the children experienced all the plays, they were interviewed to reflect the experience. The interview was conducted a week later and the children still remembered it well. It was showed from the way they told again the stages and rules of the play exactly as they experienced it. All children stated that it was their first time engaging the play. The data also showed that the children had enjoyed the play and had fun with it. Some children stated that they got exhausted with the play. One child said," I lost my breath because I have to run here and there to avoid the ball".

The interview also revealed that children basically aware of the values carried out in the play. There were three values the children aware of from the play. The first was Sportive/honest. Some children especially girls noted that when they became attacker team, they had to keep their eyes to the defender boys because boys tended to be cheated by ruining again the arrangement of the broken tiles. One girl said "I am angry to the boys because they cheated"

The children explained that we could not cheat in the play. So being an honest person was important for them. The second value was cooperative. They described that they had to help each other as members in a team. Two children stated that they had to work together to arrange the broken tiles and they had to tell their friends to watch out the ball. One child described that he should hand in hand with his friends in throwing the ball to hit the attacker team. The third value was strategy. It was shown from the student's explanation related to how to throw the ball to make the broken tiles fall down and how to throw the ball to the attacker team. Some children said that it was quite difficult to make the broken tiles fall down sometimes it was their luck the broken tiles could be hit and fallen. In relation to throwing the ball to the attacker team, three children mentioned that they should throw it hardly if the attacker team ran too far from them. The fourth value was the social interaction. Two children remembered and explained names of their friends 
who were in the same team. It showed their awareness of members of the team and whom they should cooperate with.

In relation to the critical thinking process, the aspects that described by Fisher (2006 in Roche, 2015: 14) showed in the data that the children's collaborative aspect emerged. It was seen from the way they worked together with their friends to arrange the fallen broken tiles. The data illustrated the process of discussing which was the first tile piece to be placed first and so on and so forth. The children worked collaboratively in terms of deciding the arrangement of the tile. Another aspect revealed was critical. The data from the interview exemplified the children's explanation related to the reason they like and enjoy the activity of playing the traditional play. Most of them said that this was their first time they played the traditional play and they had a great time. They also asked for more time to play again as they enjoyed so much and did not realize as the time was up. They also described the need to work together with other members in a team that was to win the play. The girl explanation related to the awareness of some boys cheated in the play also described the aspect of critical. The data also described the aspect of creative of the children. Children tried their best to avoid the ball to hit them. Deciding where to run, how to move their body to avoid the ball, how to arrange the broken tiles, how to throw the ball to hit another team needed the children's strategy. Hence it was considered as creative as they built ideas to solve the problem. Another value that emerged was caring. The children awareness of self and care of others showed in the observation. They stopped the play when they saw their friend fell down or cried. One child asked another child whether he was okay or not as his friend cried because of getting hit by the ball. Another girl asked one of their friends who looked confuse because of not belonging to their teams. They asked their friend to join their team. The findings show that the children basically are able to reflect the experience they had clearly. They enjoy the play as it involves direct experiences, hands-on physical activities, in a fun and enjoyable situation. Moreover, they also aware of the values as an implied moral lesson they got from playing the traditional play. The children also motivated to be critical thinkers as there were some activities that revealed their thinking skill.

\section{CONCLUSIONS}

Promoting critical thinking through experiential learning for children should be started as early as possible. The children involved in direct experience and hand-on physical activities. Play is one way to promote critical thinking in a fun and active activities. The students experienced traditional play to facilitate their thinking skill. Furthermore, traditional play involved the children into the values of traditional philosophies such as sportively, cooperative, strategic, social interaction. Some aspects of critical thinking skill also promoted as the activities motivated the children to think critically.

\section{ACKNOWLEDGEMENTS}

This study was funded by the Indonesia higher education (DIKTI) and still in research progress.

\section{REFERENCES}

Brookfield, Stephen D. (1987). Developing Critical Thinkers. USA: Open University Press.

Cottrell, Stella. (2005). Critical Thinking Skills: Developing Effective Analysis and Argument. Palgrave Macmillan

Ennis, Robert H. (1996). Critical Thinking. USA: University of Illinois.

Illeris, K. (2007). What do we actually mean by experiential learning. Human Resource Development Review Vol. 6, No. 1 March 2007 84-95 Sage Publications

Kolb, A. Y., \& Kolb, D. A. (2005). Learning styles and learning spaces: Enhancing experiential learning in higher education. Academy of Management Learning \& Education, 4, 193-212.

Kolb, D. A. (1984). Experiential learning: Experience as thesource of learning and development. Englewood Cliffs, NJ : Prentice Hall.

Lewis and William. (1994). Experiential Learning:Past and Present. New directions for adult and continuing education, No. 62. Summer, 1994.

Plantinga, J. \& Trainor, L.J. (2008). Infants' memory for isolated tonesand the effects of interference. Music Perception, 26,121 - 8.

Plowman, L, McPake, J \& Stephen, C. (2010). The tecnologisation of childhood? Young children and technology in the home. Children and Society 24 (1) 63 - 74

Roche, Mary. (2015). Developing Children's Critical Thinking Through Picturebooks. NewYork: Routledge.

Seaman. (2008). Experience, Reflect, Critique: The end of the "learning cycles" era. Journal of Experiential Education, 31, 3-18.

Sternberg, R.J. (1986). Critical Thinking: its Nature, Measurement, and Improvement. ERIC Journal. Retrieved from https://eric.ed.gov/?id=ED272882 
